\title{
Assessment of APACHE II Score to Predict ICU Outcomes of Patients with AKI: A Single-center Experience from Haryana, North India
}

\author{
Paras Patel ${ }^{1} \odot$, Sunita Gupta ${ }^{2} \odot$ Happy $^{\text {Patel }}{ }^{3} \odot$, MD. Abu Bashar ${ }^{4} \odot$
}

\begin{abstract}
Background: The acute physiology and chronic health evaluation (APACHE) II severity score has shown a good calibration and discriminatory value across a range of disease processes and remains the most widely used source of prognostic information on the risk for death in patients admitted to intensive care units (ICUs).

Objectives: To study APACHE II scores in patients of acute kidney injury (AKI) admitted in the ICU and to find its association with outcome. Materials and methods: One hundred patients with AKI aged 18 years or above were admitted in the ICU, department of general medicine, of a tertiary care institute in Haryana, North India, from October 2019 to September 2020, were studied. Patients who had known causes of chronic kidney disease (CKD), on maintenance hemodialysis, and those who underwent renal replacement therapy (RRT) or nephrectomy were excluded. All required investigations were performed, and data were collected. The patients were followed till discharge or in-hospital mortality. Results: The mean age of the patients was $55.92 \pm 18.18$ years. Male-female ratio was 1.5:1. Thirty-five percent of the admitted patients had an in-hospital mortality. Sepsis (47\%) was the most common cause of AKI, and $83 \%$ of the patients had underlying comorbid conditions. The mean APACHE II score of the expired patients on admission, i.e., $24.80 \pm 13.65$, was found to be significantly higher compared to the mean APACHE II score $(17.25 \pm 10.12$ ) of the discharged patients ( $p$-value $<0.001)$. APACHE II score was found to have $57.14 \%$ sensitivity, $86.15 \%$ specificity, $69 \%$ PPV, 78.9\% NPV, and 76\% diagnostic accuracy to predict mortality among the AKI patients.

Conclusion: APACHE II scoring system has a good discrimination and calibration when applied to ICU-admitted AKI patients and is a good predictor of prognosis in them.

Keywords: Acute kidney injury, APACHE II score, Critical care, KDIGO stages, Mortality.

Indian Journal of Critical Care Medicine (2022): 10.5005/jp-journals-10071-24142
\end{abstract}

\section{INTRODUCTION}

Acute kidney injury (AKI) is a rapid decrease in kidney function over hours to days, due to an injury that causes functional or structural changes in the kidneys, resulting in an inability to maintain acid-base, fluid, and electrolyte balance and to excrete nitrogenous wastes. ${ }^{1} \mathrm{AKI}$ affects more than 13 million people every year globally and results in around 1.7 million deaths., ${ }^{2,3} \mathrm{AKI}$ is diagnosed in up to $20 \%$ of the hospitalized patients ${ }^{4}$ and $30-60 \%$ of critically ill patients. ${ }^{5,6}$ It is the most frequent cause of organ dysfunction in the intensive care unit (ICU), and the occurrence of even mild AKI is associated with a $50 \%$ higher risk of death. ${ }^{7}$ AKI leads to a significant burden for the society in terms of health resource use and expenditure during the acute phase and the potential long-term complication including the development of chronic kidney disease (CKD) and kidney failure. ${ }^{8-10}$

The acute physiology and chronic health evaluation (APACHE) II score was developed by the US researchers led by Knaus et al. ${ }^{11}$ This score ranges from 0 to 71 and includes weightage for age, past comorbid conditions, and acute physiological parameters. ${ }^{11}$ The APACHE II severity score has shown a good calibration and discriminatory value across a range of disease processes and remains the most widely used source of prognostic information on the risk for death of patients admitted to ICUs. ${ }^{12}$ In a recent study from China, APACHE II has been found to be an effective clinical tool to predict hospital mortality in patients with coronavirus disease 2019 compared with sequential organ failure assessment score and
1,2Department of General Medicine, MM Institute of Medical Sciences and Research, Ambala, Haryana, India

${ }^{3}$ Department of Obstetrics and Gynaecology, Shri Vinova Bhave Civil Hospital, Silvaasa, Dadar and Nagar Haveli, India

${ }^{4}$ Department of Community Medicine and Family Medicine, All India Institute of Medical Sciences, Gorakhpur, Uttar Pradesh, India

Corresponding Author: Sunita Gupta, Department of General Medicine, MM Institute of Medical Sciences and Research, Ambala, Haryana, India, e-mail: sunitaguptamedicine@gmail.com

How to cite this article: Patel P, Gupta S, Patel H, Bashar MDA. Assessment of APACHE II Score to Predict ICU Outcomes of Patients with AKI: A Single-center Experience from Haryana, North India. Indian J Crit Care Med 2022;26(3):276-281.

Source of support: Nil

Conflict of interest: None

CURB65 score. ${ }^{13}$ It has the advantage of being easy to use and has been used more frequently for risk stratification in AKI than other similar scoring systems. Furthermore, the APACHE II score has traditionally been performed at the time of admission to the ICU, whereas the prognosis of patients with AKI may best be determined on the day of admission.

Nowadays, the KDIGO classification system is one of the most recent developments in defining $\mathrm{AKI}$ and its severity. ${ }^{13} \mathrm{~A}$ number of studies have been conducted globally for assessing KDIGO

() The Author(s). 2022 Open Access This article is distributed under the terms of the Creative Commons Attribution 4.0 International License (https://creativecommons. org/licenses/by-nc/4.0/), which permits unrestricted use, distribution, and non-commercial reproduction in any medium, provided you give appropriate credit to the original author(s) and the source, provide a link to the Creative Commons license, and indicate if changes were made. The Creative Commons Public Domain Dedication waiver (http://creativecommons.org/publicdomain/zero/1.0/) applies to the data made available in this article, unless otherwise stated. 
classification in predicting the outcomes in patients with AKI admitted in the ICUs.

However, such studies are very few in our settings where burden of AKI is very high. Therefore, we decided to study the overall mortality of patients with $\mathrm{AKI}$ in ICU, comparison of mortality in AKI according to the severity staging by KDIGO, contributory factors, etiological profiles, and the assessment of APACHE II to predict outcomes among those patients.

\section{Materials and Methods}

The present study was a hospital-based prospective observational study conducted at a tertiary care teaching and research institute in the state of Haryana, North India, over a period of 1 year. A total of 100 patients of AKI admitted in the ICU of the department of general medicine between October 2019 and September 2020 were studied. Patients aged $\geq 18$ years fulfilling the inclusion criteria were enrolled into the study after obtaining a written informed consent.

\section{Inclusion Criteria}

- ICU-admitted patients whose serum creatinine level increased $\geq 0.3 \mathrm{mg} / \mathrm{dL}$ within 48 hours of admission or

- Patients whose urine output decreased $<0.5 \mathrm{~mL} / \mathrm{kg} / \mathrm{hour}$ for $>6$ hours or

- Patients having increase in serum creatinine level $\geq 1.5$ times from baseline, which is presumed to occur within seven prior days

- Age $\geq 18$ years

\section{Exclusion Criteria}

- Known case of CKD

- Patient was on maintenance hemodialysis

- Patients who underwent renal replacement or nephrectomy

Detailed clinical history was taken, and clinical examination was performed for all the enrolled patients. Following investigations were performed for all the patients at the time of admission: complete blood count (CBC), liver function test (LFT), renal function test (RFT), chest X-ray, ultrasound abdomen, fluid intake, and urine output measurement, urine routine examination, urine and blood culture and sensitivity, and arterial blood gas analysis (ABG). Subsequent serum creatinine levels were also done during the hospital stay. AKI was categorized as per AKI-KDIGO severity classification. The etiology of AKI was also recorded. Wherever the patient required renal replacement therapy, ionotropic support, or ventilator support, they were also recorded. APACHE II scores were calculated at the time of admission. Patients were followed till discharge from the hospital or occurrence of in-hospital mortality. All data were collected and recorded in a pretested semi-structured questionnaire developed by the authors.

\section{Statistical Analysis}

Data were entered in Excel spreadsheets and were analyzed using SPSS version 21.0. Quantitative variables were compared using the independent $t$-test/Mann-Whitney $U$-test between the discharged and the expired group. Qualitative variables were compared using the Chi-square test/Fisher's exact test. The receiver operating characteristic $(R O C)$ curves were made to find out the cutoff point of APACHE II score for predicting mortality. The area under the ROC curve was calculated for APACHE score using the DeLong test. $p$-value $<0.05$ was considered statistically significant.

\section{Ethical Considerations}

The study protocol was approved by Institute Ethics Committee (IEC), MM Institute of Medical Sciences and Research, Mullana, vide letter No. IEC/1223/2018. Written informed consent was obtained from patients' legal representative after explaining the objectives and procedures of the study before inclusion of the patient in the study. All the data collected were kept confidential.

\section{Results}

The mean age of ICU-admitted AKI patients was $55.92 \pm 18.12$ years with majority ( $41 \%)$ being $\geq 60$ years. Male-female ratio was 1.5:1. The overall in-hospital mortality was $35 \%$, and $65 \%$ of patients were discharged alive from the hospital.

With respect to underlying etiology, $47(47 \%)$ patients had sepsis, 21 (21\%) had cardiogenic shock, 7 (7\%) had hypertensive nephropathy, $6(6 \%)$ patients had hepatorenal syndrome, hypovolemia, and nephrotoxic drugs/contrast-induced and obstructive uropathy each, and 1 (1\%) patient had developed AKI postsurgery (Table 1). Patients developing AKI due to cardiogenic shock had the highest mortality rate of $61.9 \%$.

Comorbid conditions associated with AKI were CAD in 19\%, COPD in $11.9 \%$, CLD in $4 \%$, anemia in $6 \%$, AIDS in $1 \%$, CVA in $8 \%$, diabetes mellitus in $6 \%$, HTN in $18 \%$, malignancy in $5 \%$, postsurgery in $4 \%$, and SLE $1 \%$ patients. The mortality rate was highest (52.6\%) among patients with CAD. Although mortality was higher among patients with comorbid condition compared to patients who did not have any comorbid condition, the difference was statistically nonsignificant ( $p=0.78$ ).

With respect to KDIGO staging of the patients, 37 (37.0) were in stage I, 25 (25.0\%) were in stage II, and rest 38 (38.0\%) were in stage III (Table 2). There was no significant difference observed across

Table 1: Underlying etiology of AKI among the ICU-admitted patients $(N=100)$

\begin{tabular}{llc}
\hline SI. No. & Etiology & Frequency (\%) \\
\hline 1 & Sepsis & $47(47.0)$ \\
2 & Cardiogenic shock & $21(21.0)$ \\
3 & Hypertensive nephropathy & $7(7.0)$ \\
4 & Hepatorenal syndrome & $6(6.0)$ \\
5 & Hypovolemia & $6(6.0)$ \\
6 & Nephrotoxic drugs/contrast & $6(6.0)$ \\
7 & Obstructive nephropathy & $6(6.0)$ \\
8 & Postsurgey & $1(1.0)$ \\
& Total & $100(100.0)$ \\
\hline
\end{tabular}

Table 2: Association of KDIGO staging with the outcome in ICU-admitted AKI patients $(N=100)$

\begin{tabular}{lccrl}
\hline $\begin{array}{l}\text { KDIGO } \\
\text { stage }\end{array}$ & Dischargedn(\%) & Expiredn(\%) & Total $n(\%)$ & $X^{2}, p$ value \\
\hline 1 & $24(64.9)$ & $13(35.1)$ & $37(100.0)$ & $1.542,0.48$ \\
2 & $14(56.0)$ & $11(44.0)$ & $25(100.0)$ & \\
3 & $27(71.0)$ & $11(29.0)$ & $38(100.0)$ & \\
Total & $65(65.0)$ & $35(35.0)$ & $100(100.0)$ & \\
\hline
\end{tabular}


the various KDIGO stages with respect to outcome ( $p=0.48)$. So, mortality was not affected with the increasing severity of AKI as per KDIGO classification.

With respect to APCHE II scores of the patients, maximum patients (29\%) had scores between 15 and 19 followed by 20-24 (22\%) (Table 3). Mortality increased with increasing APACHE II scores, and $100.0 \%$ mortality was observed with a score $>34$. A highly significant difference was observed in the proportion of discharged and expired patients across the APACHE II score categories $(p<0.0001)$ with number of expired patients increasing with increasing APACHE II score.

With respect to association of APACHE II scores with KDIGO staging, mean APACHE II scores of the expired patients were significantly higher than mean APCHE II scores of discharged patients across all the three AKI stages as per KDIGO classification system (Table 4).

The degree of discrimination among discharged and the expired patients was calculated using the area under the ROC curve (AUC). The discriminatory power of APACHE II score on admission (AUC 0.79; 95\% Cl: 0.697-0.865) was acceptable (Fig. 1). APACHE II score on admission was the best predictor of mortality at the cutoff point value of $>23$ with $79.00 \%$ chances of correctly predicting mortality. APACHE II score had $57.14 \%$ sensitivity, $86.15 \%$ specificity, 69\% PPV, 78.9\% NPV, and 76\% diagnostic accuracy to predict mortality (Table 5 ).

Parameters such as higher pulse rate, higher respiratory rate, and low mean arterial pressure had a strong association with the mortality $(p<0.05)$. Need for ventilatory and ionotropic support, lower GCS score on admission, and higher APACHE II score were also found to be significant parameters predicting mortality (Table 6).

Table 3: Association of APACHE II scores on admission with the outcome in ICU-admitted AKI patients $(N=100)$

\begin{tabular}{lccrl}
\hline $\begin{array}{l}\text { APACHE II } \\
\text { scores on } \\
\text { admission }\end{array}$ & $\begin{array}{c}\text { Discharged } \\
(n=65)\end{array}$ & $\begin{array}{c}\text { Expired } \\
(n=35)\end{array}$ & & \\
\hline $0-4$ & $1(100.0)$ & $0(0.0)$ & $1(100.0)$ & $<0.0001$ \\
$5-9$ & $3(100.0)$ & $0(0.0)$ & $3(100.0)$ & \\
$10-14$ & $19(95.0)$ & $1(5.0)$ & $20(100.0)$ & \\
$15-19$ & $20(68.9)$ & $9(31.1)$ & $29(100.0)$ & \\
$20-24$ & $15(68.2)$ & $7(31.8)$ & $22(100.0)$ & \\
$25-29$ & $6(42.8)$ & $8(57.1)$ & $14(100.0)$ & \\
$30-34$ & $1(14.3)$ & $6(85.7)$ & $7(100.0)$ & \\
$>34$ & $0(0.0)$ & $4(100.0)$ & $4(100.0)$ & \\
Total & $65(65.0)$ & $35(35.0)$ & $100(100.0)$ & \\
\hline
\end{tabular}

Table 4: Association of APACHE II score on admission with KDIGO staging among ICU-admitted AKI patients $(N=100)$

\begin{tabular}{lcccl}
\hline & \multicolumn{3}{c}{ APACHE II score } & \\
\cline { 2 - 4 } KDIGO & $\begin{array}{c}\text { Discharged } \\
(n=65)\end{array}$ & $\begin{array}{c}\text { Expired } \\
(n=35)\end{array}$ & $\begin{array}{c}\text { Total } \\
(n=100)\end{array}$ & \\
stages & Mean $\pm S D$ & Mean $\pm S D$ & Mean $\pm S D$ & $p$ value \\
\hline Stage I & $17.08 \pm 5.35$ & $24.15 \pm 7.58$ & $19.57 \pm 7.01$ & 0.007 \\
Stage II & $17.64 \pm 7.33$ & $24.45 \pm 9$ & $20.64 \pm 8.65$ & 0.069 \\
Stage III & $17.15 \pm 5.17$ & $25.82 \pm 4.64$ & $19.66 \pm 6.36$ & 0.0002 \\
\hline
\end{tabular}

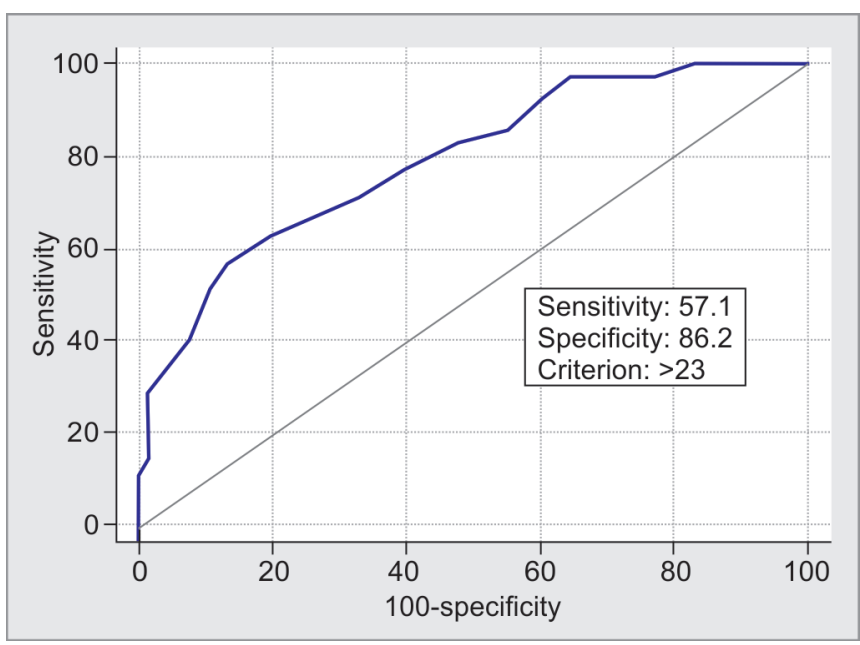

Fig. 1: ROC curve of APACHE II score to predict mortality in the AKI patients

Table 5: ROC curve characteristics of APACHE II scores to predict mortality among ICU-admitted AKI patients $(N=100)$

\begin{tabular}{lc}
\hline Parameters & Values \\
\hline Area under the ROC curve (AUC) & 0.79 \\
Standard error & 0.047 \\
$95 \%$ confidence interval & $0.697-0.865$ \\
$p$ value & $<0.0001$ \\
Cutoff & $>23$ \\
Sensitivity $(95 \% \mathrm{Cl})$ & $57.14 \%(39.4-73.7 \%)$ \\
Specificity $(95 \% \mathrm{Cl})$ & $86.15 \%(75.3-93.5 \%)$ \\
PPV $(95 \% \mathrm{Cl})$ & $69 \%(49.2-84.7 \%)$ \\
NPV $(95 \% \mathrm{Cl})$ & $78.9 \%(67.6-87.7 \%)$ \\
Diagnostic accuracy & $76.00 \%$ \\
\hline
\end{tabular}

\section{Discussion}

AKI is diagnosed in $30-60 \%$ of hospitalized critically ill patients. The epidemiology of AKI varies because of differences in demographics, social, and cultural factors. AKI is the most frequent cause of organ dysfunction in ICUs, so even mild AKI is associated with a $50 \%$ higher risk of death. ${ }^{14}$

In our study, the mean age of ICU-admitted AKI cases was $55.92 \pm 18.12$ years and the majority of the patients $(41 \%)$ were $\geq 61$ years. The other similar studies by Rakesh Bhadade et al., ${ }^{15}$ Eswarappa et al., ${ }^{16}$ and Saxena et al. ${ }^{17}$ showed that mean age of ICU-admitted AKI patients varies between 42 and 68 years.

We observed that as age increases, the incidence of AKI also increases which may be due to a decrease in GFR and increase in the incidence of underlying comorbid conditions such as HTN, DM, $C A D$, and malignancy.

We categorized all the study subjects according to KDIGO classification which is also used to Sreenath et al. ${ }^{18}$ and Tejera et al. ${ }^{19}$ to classify the AKI patients. Distribution of patients according to stages of AKI in ICU varies widely among the studies, and it might be due to differences in methodology and heterogeneous studied population nature, clinical profile of patients, and underlying 
APACHE II Score to Predict Prognosis among Acute Kidney Injury Patients

Table 6: Comparison of various parameters for predicting outcome in ICU-admitted AKI patients $(N=100)$

\begin{tabular}{lcccc}
\hline Parameters & Discharge group (Mean \pm SD) & Expired group (Mean \pm SD) & Total (Mean \pm SD) & $p$ value \\
\hline Pulse rate (per minute) & $96.63 \pm 20.51$ & $113.4 \pm 18.38$ & $102.5 \pm 21.27$ & 0.0001 \\
Respiratory rate (per minute) & $21.91 \pm 5.25$ & $25.03 \pm 5.62$ & $23 \pm 5.56$ & 0.004 \\
$\mathrm{FiO}_{2} \%$ & $29.69 \pm 11.87$ & $43.43 \pm 18.81$ & $34.51 \pm 16.12$ & $<0001$ \\
$\mathrm{MAP}(\mathrm{mm} \mathrm{Hg})$ & $86.64 \pm 25.34$ & $70.62 \pm 31.42$ & $81.03 \pm 28.51$ & 0.03 \\
GCS on admission & $13.6 \pm 2.67$ & $11.17 \pm 4.6$ & $12.75 \pm 3.64$ & 0.009 \\
Age (years) & $54.83 \pm 18.11$ & $57.94 \pm 18.03$ & $55.92 \pm 18.05$ & 0.413 \\
TLC (per cumm) & $17809.52 \pm 9545.91$ & $15768.86 \pm 7294.41$ & $17095.29 \pm 8839.64$ & 0.63 \\
Blood urea $(\mathrm{mg} / \mathrm{dL})$ & $146.21 \pm 113.18$ & $125.71 \pm 73.11$ & $139.03 \pm 101.06$ & 0.605 \\
Initial serum creatinine $(\mathrm{mg} / \mathrm{dL})$ & $4.27 \pm 3.13$ & $2.94 \pm 1.31$ & $3.81 \pm 2.71$ & 0.128 \\
APACHE Il score & $17.25 \pm 10.12$ & $24.80 \pm 13.65$ & $19.55 \pm 11.45$ & $<0.001$ \\
\hline
\end{tabular}

comorbid conditions, and it also depended upon time delay in availability of ICU care facilities.

In our study, the potential risk of AKI was higher in patients who had comorbid conditions such as CAD, HTN, COPD, and CVA compared to patients with AIDS, anemia, CLD, diabetes mellitus, malignancy, postsurgery, or SLE. We found that underlying comorbid conditions had a higher mortality rate of $36.15 \%$ and patients with CAD had the highest mortality rate of $52.63 \%$. So, CAD was one of the independent predictors of mortality in ICUadmitted AKI Patients. Saxena et al. ${ }^{17}$ reported the association of comorbid conditions, i.e., HTN, DM, and ischemic heart disease with mortality among the ICU-admitted AKI patients. Susantitaphong et al. and Wijewickrama et al. ${ }^{20}$ also reported a higher incidence of AKI in patients of cardiovascular disease and hypertension. Therefore, the outcome of the comorbid condition of AKI patients also depended on the underlying course of the disease and multisystem involvement.

In our study, most common underlying etiology of AKI in ICUadmitted patients was sepsis (47.0\%). Studies by Kapadia et al. ${ }^{21}$ and Chawla et al. ${ }^{22}$ also found sepsis as the most common cause of AKI in ICU-admitted patients.

In our study, the mean APACHE II scores of the expired patients were found to be significantly higher than those of discharged patients in all the KDIGO stages. However, the mean APACHE II scores were not increasing according to AKI severity as per KDICO stages. Studies by Bhadade et al., ${ }^{15}$ Maher et al., ${ }^{23}$ and Abosaif et al. ${ }^{24}$ also showed that the APACHE II scores were significantly higher in the expired group as compared to the discharged or alive group.

Our study showed that the APACHE II score had 57.14\% sensitivity to predict mortality and $79.00 \%$ probability of correctly predicting mortality at cutoff value of 23. Different studies showed that the APACHE II score had sensitivity from 51 to $93 \%$ and specificity ranges from 49 to $97 \% .{ }^{25}$ Our finding is comparable with the finding by Hashemian et al. ${ }^{26}$

In our study, ventilatory support and ionotropic support were found to be strong predictors of mortality in AKI patients ( $p$-value $<0.001)$. In the study of Korula et al., ${ }^{27}$ the use of vasopressors (noradrenaline) was found to be an independent predictor of mortality in ICU-admitted AKI patients and requirement of mechanical ventilatory support was found to have a significant relation with mortality.

We found lower GCS score was associated with in-hospital mortality in AKI patients which was consistent with the results of the previous studies done by Saxena et al., ${ }^{17}$ Pan et al., ${ }^{28}$ Lin et al., ${ }^{29}$ Sezer et al., ${ }^{30}$ Samimagham et al., ${ }^{31}$ Shiao et al., ${ }^{32}$ and Friedericksen et al. ${ }^{33}$

In our study, pulse rate and respiratory rate were significantly higher in expired patients compared to discharged ones, and $\mathrm{FiO}_{2} \%$ and mean arterial pressure (MAP) were significantly lower in expired patients compared to discharged ones. However, parameters such as TLC count, platelet count, initial blood urea, and serum creatinine levels were not found to be significantly different between the expired and discharged patients. Kapadia et al. ${ }^{21}$ also reported a higher pulse rate and respiratory rate in expired patients.

\section{Limitations}

This was a single-center, prospective study of only 1-year duration. Further, the follow-up period was limited to duration of hospitalization which was somewhat small to know whether the kidneys have recovered or the patients required long-term RRT. A larger multicenter study with longer follow-up can provide a more strong association between the APACHE II severity scores and outcome of ICU-admitted AKI patients. Furthermore, comparison of APACHE II score with other prognostic scoring system such as SOFA score and CURB65 score could have given a better picture on the discriminatory ability of APACHE II score in predicting mortality.

\section{ConCLUSion}

The overall mortality rate of the ICU-admitted AKI patients was $35 \%$ in our study. APACHE II scoring system has a good discrimination and calibration when applied to ICU-admitted AKI patients and is a good predictor of mortality in ICU-admitted AKI patients. Other predictors of mortality are higher pulse rate, higher respiratory rate, low mean arterial pressure, a requirement of ventilatory and ionotropic support, and lower GCS score.

\section{Declarations}

\section{Ethics Approval and Consent to Participate}

The study protocol was approved by Institute Ethics Committee (IEC), vide letter No. IEC/1223/2018. Written informed consent was taken from the patient's legal representative before enrolment in the study.

\section{Consent for Publication}

Not applicable. 


\section{Availability of Data and Material Data}

Data pertaining to the study are with corresponding author which can be accessed on reasonable request.

\section{Authors' Contributions}

PP and SG conceived the idea of the study. PP and HP performed the literature review. PP performed the data collection and analysis. PP wrote the first draft which was edited and improved by MAB and SG. All authors approved the final draft for submission.

\section{ACKNOWLedgments}

Authors would like to thank acknowledge support provided by Dr BK Aggarawal, Principal, MM Institute of Medical Sciences and Research, Mullana, in conducting the study.

\section{ORCID}

Paras Patel (1) https://orcid.org/0000-0002-5670-2840

Sunita Gupta $\odot$ https://orcid.org/0000-0002-2555-1285

Happy Patel ৫ https://orcid.org/0000-0001-9078-9129

MD. Abu Bashar @ https://orcid.org/0000-0002-0868-8335

\section{References}

1. Chugh KS. Renal disease in India. Am J Kidney Dis 1998;31(3):Ivii-lix. PMID: 9506675.

2. Lameire NH, Bagga A, Cruz D, Maeseneer JD, Endre Z, Kellum JA, et al. Acute kidney injury: an increasing global concern. Lancet 2013;382(9887):170-179. DOI: 10.1016/S0140-6736(13)60647-9.

3. Lewington AJ, Cerdá J, Mehta RL. Raising awareness of acute kidney injury: a global perspective of a silent killer. Kidney Int 2013;84(3): 457-467. DOI: 10.1038/ki.2013.153.

4. Susantitaphong P, Cruz DN, Cerda J, Abulfaraj M, Alqahtani F, Koulouridis I, et al. World incidence of AKI: a meta-analysis [published correction appears in Clin J Am Soc Nephrol 2014;9(6):1148]. Clin J Am Soc Nephrol 2013;8(9):1482-1493. DOI: 10.2215/CJN.00710113.

5. Singbartl K, Kellum JA. AKI in the ICU: definition, epidemiology, risk stratification, and outcomes. Kidney Int 2012;81(9):819-825. DOI: 10.1038/ki.2011.339.

6. Hoste EA, Bagshaw SM, Bellomo R, Cely CM, Colman R, Cruz DN, et al. Epidemiology of acute kidney injury in critically ill patients: the multinational AKI-EPI study. Intensive Care Med 2015;41(8):1411-1423. DOI: 10.1007/s00134-015-3934-7.

7. Linder A, Fjell C, Levin A, Walley KR, Russell JA, Boyd JH. Small acute increases in serum creatinine are associated with decreased long-term survival in the critically ill. Am J Respir Crit Care Med 2014;189(9):1075-1081. DOI: 10.1164/rccm.201311-2097OC.

8. Bellomo R, Kellum JA, Ronco C. Acute kidney injury. Lancet 2012;380(9843):756-766. DOI: 10.1016/S0140-6736(11)61454-2.

9. Murugan R, Kellum JA. Acute kidney injury: what's the prognosis? Nat Rev Nephrol 2011;7(4):209-217. DOI: 10.1038/nrneph.2011.13.

10. Chawla LS, Eggers PW, Star RA, Kimmel PL. Acute kidney injury and chronic kidney disease as interconnected syndromes. N Engl J Med 2014;371(1):58-66. DOI: 10.1056/NEJMra1214243.

11. Knaus WA, Draper EA, Wagner DP, Zimmerman JE. APACHE II: a severity of disease classification system. Crit Care Med 1985;13(10):818-829. PMID: 3928249.

12. Bouch DC, Thompson JP. Severity scoring systems in the critically ill. Continu Educ Anaesth Crit Care Pain 2008;8(5):181-185. DOI: 10.1093/ bjaceaccp/mkn033.

13. Ricci Z, Romagnoli S. Acute kidney injury: diagnosis and classification in adults and children. Contrib Nephrol 2018;193:1-12. DOI: 10.1159/000484956.
14. Kellum JA, Lameire N, Aspelin P, Barsoum RS, Burdmann EA Goldstein $\mathrm{SL}$, et al. Kidney disease: improving global outcomes (KDIGO) acute kidney injury workgroup. KDIGO clinical practice guideline for acute kidney injury. Kidney Int Suppl 2012;2(1):1-38. DOI: 10.1038/kisup.2012.1.

15. Bhadade R, De'Souza R, Harde MJ, Mehta KS, Bhargava P. A prospective study of acute kidney injury according to KDIGO definition and its mortality predictors. J Assoc Physicians India 2016;64(12):22. PMID: 28405984

16. Eswarappa M, Gireesh MS, Ravi V, Kumar D, Dev G. Spectrum of acute kidney injury in critically ill patients: a single-center study from South India. Indian J Nephrol 2014;24(5):280. DOI: 10.4103/09714065.132991.

17. Saxena A, Meshram SV. Predictors of mortality in acute kidney injury patients admitted to medicine intensive care unit in a Rural Tertiary Care Hospital. Indian J Crit Care Med 2018;22(4):231. DOI: 10.4103/ ijccm.IJCCM_462_17.

18. Sreenath S, Santhosh KumarTS, Retheesh Kumar. KDIGO classification in predicting the outcomes of acute kidney injury in patients in intensive care units of a tertiary care centre. IAIM 2018;5(8):30-40. Available from: https://iaimjournal.com/wp-content/uploads/2018/08/ iaim_2018_0508_04.pdf

19. Tejera D, Varela F, Acosta D, Figueroa S, Benencio S, Verdaguer C, et al. Epidemiology of acute kidney injury and chronic kidney disease in the intensive care unit. Rev Bras Ter Intensiva 2017;29(4):444-452. DOI: 10.5935/0103-507X.20170061.

20. Wijewickrama ES, Ratnayake GM, Wikramaratne C, Sheriff R, Rajapakse $\mathrm{S}$. Incidences and clinical outcomes of acute kidney injury in ICU: a prospective observational study in Sri Lanka. BMC Res Notes 2014;7(1):305. DOI: 10.1186/1756-0500-7-305.

21. Kapadia MP, Kamdar KP, Jha PR. A study of clinical profile of patients with acute kidney injury in a tertiary care centre. IJASR [serial online] 2016;2(8):160-166. DOI: 10.7439/ijasr.v2i8.3511.

22. Chawla LS, Abell L, Mazhari R, Egan M, Kadambi N, Burke HB, et al. Identifying critically ill patients at high risk for developing acute renal failure: a pilot study. Kidney Int 2005;68(5):2274-2280. DOI 10.1111/j.1523-1755.2005.00686.x.

23. Maher ER. Robinson KN, Scoble JE, Farrimond JG, Browne DR, Sweeny $\mathrm{P}$, et al. Prognosis of critically ill patients with acute renal failure: APACHE II score and other predictive factors. QJM 1989;72(269): 857-866. PMID: 2616731.

24. Abosaif NY, Tolba YA, Heap M, Russell J, El Nahas AM. The outcome of acute renal failure in the intensive care unit according to RIFLE: model application, sensitivity, and predictability. Am J Kidney Dis 2005;46(6):1038-1048. DOI: 10.1053/j.ajkd.2005.08.033.

25. Haniffa R, Isaam I, De Silva AP, Dondorp AM, De Keizer NF. Performance of critical care prognostic scoring systems in low and middle-income countries: a systematic review. Crit Care 2018;22(1):18. DOI: 10.1186/ s13054-017-1930-8.

26. Hashemian SM, Jamaati H, Bidgoli BF, Farrokhi FR, Malekmohammad M, Roozdar S, et al. Outcome of acute kidney injury in critical care unit, based on AKI network. Tanaffos 2016;15(2):89. PMID 27904540

27. Khan MY, Deepak P, Kumar AP, TV KK. Study of etiology, clinical profile and outcome of acute kidney injury (AKI) in medical intensive care unit. IJCMR 2017:4(11):2225. Available from:https://www.ijcmr.com/ uploads/7/7/4/6/77464738/ijcmr_1742_v1.pdf

28. Korula S, Balakrishnan S, Sundar S, Paul V, Balagopal A. Acute kidney injury-incidence, prognostic factors, and outcome of patients in an Intensive Care Unit in a tertiary center: a prospective observational study. Indian J Crit Care Med 2016;20(6):332. DOI: 10.4103/09725229.183904

29. Shiao CC, Ko WJ, Wu VC, Huang TM, Lai CF, Lin YF, et al. U-curve association between timing of renal replacement therapy initiation and in-hospital mortality in postoperative acute kidney injury. PLoS One 2012;7(8):e42952. DOI: 10.1371/journal.pone.0042952. 
30. Sezer MT, Demir M, Gungor G, Senol A. Predictors of mortality in patients with acute renal failure. Acta Medica (Hradec Kralove) 2006;49(3):183-188. PMID: 17117607.

31. Pan HC, Jenq CC, Tsai MH, Fan PC, Chang CH, Chang MY, et al. Risk models and scoring systems for predicting the prognosis in critically ill cirrhotic patients with acute kidney injury: a prospective validation study. PLoS One 2012;7(12):e51094. DOI: 10.1371/journal.pone.0051094.
32. Lin CY, Chang CH, Fan PC, Tian YC, Chang MY, Jenq CC, et al. Serum interleukin-18 at commencement of renal replacement therapy predicts short-term prognosis in critically ill patients with acute kidney injury. PLoS One 2013;8:e66028. DOI: 10.1371/journal.pone.0066028.

33. Friedericksen DV, van der Merwe L, Hattingh TL, Nel DG, Moosa MR. Acute renal failure in the medical ICU still predictive of high mortality. S Afr Med J 2009;99(12):873-875. PMID: 20459997. 